\title{
FANTASMAS, INFLUÊNCIAS, INSPIRAÇÕES: ODYSSEUS, O VELHO, DE CARLOS NEJAR
}

\author{
José Luiz Foureaux de Souza Júnior \\ Universidade Federal de Ouro Preto
}

... E o auxílio luxuoso de um pandeiro...

(Luiz Melodia, Juventude transviada)

$\mathrm{O}$ adjetivo sofisticado é comumente utilizado em muitas situações. Eu diria que, sobretudo, naquelas em que a visualidade é o sentido mais instigado a agir. Um restaurante sofisticado - pela comida e pelo ambiente, com tudo o mais que o circunda: uma roupa sofisticada, modos sofisticados, festa sofisticada. Um adjetivo "comum" que se relaciona sempre a situações, pessoas e/ou ideias sempre tidas como "mais elaboradas", diferentes, nada comuns. O estranho é que - na espessura semântica que o discurso de Freud imprimiu ao vocábulo -, no dicionário, o verbete apresenta cinco acepções inesperadas para a palavra. $\mathrm{O}$ adjetivo, formado pelo particípio de um verbo transitivo direto remete à ideia de falsificação, burla, afetação, engano, adulteração, rebuscamento - no sentido pejorativo. Nada mais estranho quando se pensa nas situações corriqueiras em que este vocábulo é utilizado. Prova de que a linguagem é manhosa e não se deixa "dominar", de maneira alguma!

Entretanto, quando se pensa exatamente nela, a linguagem, o equívoco se desfaz, uma vez que as acepções apontam para ideias de requinte, originalidade, bom gosto, conhecimento profundo sobre a matéria de que se trata, avanço, eficiência e aprimoramento. É este o diapasão que me dá o tom do presente texto de recensão: exercício de exame crítico da obra em epígrafe. Aliás, esta aponta para uma aparente contradição de sabor bakhtiniano: "o auxílio luxuoso de um pandeiro". Os grifos, meus, ressaltam a aparente falta de sintonia entre 
os dois termos. O luxo de um pandeiro está associado à ideia de carnaval que, como festa popular, aposta na aparência desse mesmo luxo: uma fantasia para a comemoração do tríduo momesco, principalmente no Brasil. O pandeiro, instrumento popular, marca o ponto de fuga do luxo que, na letra da música de Luiz Melodia, compõe a harmonia de uma vida simples, típica da favela carioca, cenário exuberante da criação do samba, herança cultural de priscas eras. É sob esta perspectiva que venho apresentar a obra de Carlos Nejar.

A primeira impressão que tenho é a de que Camões, Dante, Homero e, em certa medida, Cervantes, passeiam pelo texto do poeta gaúcho de maneira sutil, elaborada e eficiente. Portanto, eu poderia dizer que se trata de um texto sofisticado. Odysseus, o velho é um emaranhado de referências míticas, históricas, literárias que enredam um discurso elaborado. Sua construção tange a beleza plástica da palavra. Trata-se da elaboração poética de uma epopeia, sem, necessariamente, seguir os passos clássicos do gênero. No entanto, a "essência" deste transparece clara e lucidamente em cada linha do longo poema. Estruturado em quatro conjuntos de poemas - em números variados -, remodelam a saga de um herói legendário em suas reflexões sobre a vida, suas relações, seus feitos, a mulher, o amor e a família. Cronos é a divindade que conduz o texto nas entrelinhas, tornando possível ler todo o volume "sofisticado" e primorosamente encadernado. O leitor saberá em que sentido utilizo, aqui, o adjetivo.

Carlos Nejar, membro da Academia Brasileira de Letras, é considerado um dos 37 escritores epigonais do período compreendido entre 1890-1990. Ele constrói uma voz poética emblemática e universal, de original e abundante produção lírica. O poeta encarna, de maneira muito convincente, ainda que modesta e discretamente, a síntese, sobejamente desejada e raramente alcançada, entre inovação e tradição, entre a crítica do mal-estar e a esperança. A figura do mito e da personagem que o encarna, na epopeia clássica revisitada, é uma espécie de porta-voz da simplicidade da dicção poética do autor - exata, mas sugestiva, crítica e esperançada. A criação poética do texto, intensa e passional, atinge o ápice da solidariedade humana. A figura esboçada pelas linhas dos poemas oscila entre a loucura e a santidade: espécie de túnel visualmente delirante e, simultaneamente, terrível, que leva o leitor a repensar a experiência subjetiva de um desesperado amor.

Nejar usa o discurso alegórico, gerando outra realidade paralela que redimensiona e refaz a argamassa verbal da realidade real, ora para criticá-la, ora para satirizá-la, mas sempre de forma a celebrar a experiência da existência humana, nas ondas da poesia. O poeta redimensiona os modelos e paradigmas da crítica literária, talvez com a intenção secretamente 
irônica de dissolvê-los todos, instaurando potente anarquia nos movimentos poéticos que orquestra. Sua poesia irriga o território tão reflorestado da linguagem, provocando certo translado semântico: tráfego e trânsito de símbolos, transferência de sentidos outros, sempre procurados pelo fazer poético.

Em Odysseus, o velho, a escrita de Carlos Nejar, própria dos poetas que são também videntes, é um tecido denso de imagens e ritmos com efeito dinamizante. Poeta da poesia, mais que do verso - dado que o verso costuma ser perecível - usa e abusa da palavra que fala, ou se cala, para além dos limites do verso: compósito de camadas diversas, que se entrecruzam, se dispersam, retornando sempre ao mesmo estuário, ao mesmo núcleo energético, de onde irrompem, em sequência solidária. A voz poética, no conjunto dos poemas, jamais se deixa enredar nas malhas de um texto enigmático, porque explicitamente referencial. Seu enredo poético alarga o princípio da realidade, alcançando os limites da transparência do mistério cosmogônico, telúrico mesmo. Concentrado e lúcido, o poeta encontra fórmulas exatas, em que irrompem perturbantes visões e vivências, tecendo o texto feito de palavra e sombra: poço das origens, etapa de um Gênesis particular.

Poeta do tempo, do amor, da esperança, da morte e de Deus, Nejar entretece fios de uma mesma urdidura cujo paralelo pode ser encontrado, no exercício pictórico de Bosch, dado que pinta, com palavras, a criação de um mundo arquetípico, rasurado pelo caminhar da cultura no/do Ocidente. Nesta pintura, o poeta gaúcho não denega suas origens: preocupa-se com "a poesia do homem pelo homem", o que sobressai de seu texto firme, viril, delicado e aberto, como o pampa. A variedade dos temas - amor, elegia, meditação, mística, épica - não significa dispersão, mas o domínio de um sopro poético que se adensa e refina. Não faltam idéias à poética muito particular de Carlos Nejar. O que o destaca é sua capacidade de verbalização geométrica. São as palavras, em sua bem cuidada arquitetura, que revelam a prosa poética, recortada pelo cume da construção dos poemas. Na verdade, o ritmo da frase se parece com a prosa, lírica e visual, que dá consistência a sentimentos e ideias, num ritmo inesperado. Tem-se a impressão de que o texto é a narrativa de um retorno. Este não se deixa recalcar pelas regras de uma poética "clássica", mas renova-se na sintaxe do verso livre, com ritmo em nada acelerado:

Sou teu pai. E dura tão pouco

a vida do homem.

para que não

me reconheças.

Ulisses sou 
A pontuação, escassa, é instrumento de organização visual da frase. Sua musicalidade vem da ideia que flui das palavras, criando a sensação de que o caráter prosaico das situações poeticamente desenhadas desmancha a dureza da realidade, tingindo liricamente a intenção da voz poética. Os diálogos, como no trecho acima, ainda que hermeticamente implícitos, revelam o caráter discursivo da épica, sem a subserviência à métrica e à rima. Arrisco afirmar que o sucesso de Camões, com seu trabalho de ourivessaria poética em $O s$ lusíadas, é igualmente alcançado pela aventura textual de Carlos Nejar. Em Língua Portuguesa, ambos atingem o sucesso que só se consolida com o tempo: espécie de desejada eternidade da palavra, quando orquestrada pela mão firme sonhadora do poeta. Poeta completo. A lírica e a épica coexistem na lavra poética do autor gaúcho: regional e universal, lírico e épico, simples e complexo, telúrico e oceânico, sintético e úmido. A linguagem de Nejar tem qualquer coisa de ígneo: consome, ao mesmo tempo que ilumina, a experiência humana do mito fixada no seu verso. Sua arte, reafirmo, é própria dos poetas que são também videntes: um tecido denso de imagens e ritmos. A fusão do épico com o lírico pode explicar o gosto pelo sensível que marca a dicção da voz poética. O tom subjetivo de uma possível épica, que narraria o demiúrgico, "sopra" a forma expressiva da frase.

A confecção de versos adaptáveis à situação e musicais, são propriedades da poesia de Carlos Nejar. Ele sabe dar às vozes que aparecem nos quatro "livros" o barroquismo de sua linguagem poética que hiperboliza, repete cristalizadas antíteses e dá o tom de choque de repulsão para expressar a fugacidade do tempo. Se de outras coisas não falasse, seria o amor uma das linhas mestras da força tanto épica, quanto lírica deste seu livro. Penélope também comparece como "personagem" no contexto da saga lírica enfrentada pelo velho herói em seu retorno, não tanto físico, material, épico, mas, como quer a poesia, um retorno lírico de memória e consumação:

\footnotetext{
Envelheceste

Quando o abraço de Odysseus

Te desabotoou.

O abraço não te poupou.

Envelheceste quando os vinte anos

De peixe de fisgaram pelo meio.

Ou quando vinte faróis

Girassolaram seu casco

De pensamento veleiro

Sem demorar o acaso

Nas rodas de nau e roca,
} 
Foste rejuvenescendo

Ao findar o abraço, a onda.

E mesmo no arder do gozo,

Alvos azuis sobrevoam

Os corpos. Também o espírito

Plana, jovem. Romã

No galho de onde saltas.

Com amor cerzindo

As abas da manhã. (p. 92)

Fica claro nesses versos a alusão fatídica ao amor desesperado do herói por sua escolhida. O mito gera a situação narrativa que os versos do poeta recortam em sintaxe particular. As alusões metonímicas ao mar - "peixe", "veleiro", "nau”, "onda", para ficar com apenas algumas ilações - conotam a viagem do retorno à ilha desejada, assim como, por tabela, a memória das vicissitudes da busca desesperada na viagem de ida. O tecer de Penélope - metonimizado no substantivo "roca" e no gerúndio "cerzindo", para além de referenciar a mulher, remetem à ideia de tempo, de fluxo contínuo de acontecimentos e situações que demarcam o território da própria existência. A plasticidade da frase, quebrada em versos que podem ser considerados "irregulares", não prescinde do ritmo que vem, antes, do movimento das ideias por eles veiculadas. A substituição da tradição rimático-métrica não se faz sentir, dado que o fluxo lírico do discurso se consolida na referência sempre segura ao mito, em todas as suas variações. Os versos destacados são apenas pequena amostra do universo de fantasias e experiências sensoriais que a leitura do livro de Nejar oferece ao leitor. Fica o convite para esta aventura repleta de prazer e sedução.

[Recebido em novembro de 2011 e aceito para publicação em junho de 2012]

NEJAR, Carlos. Odysseus, o velho: poemas. Porto Alegre: CiaE, 2010.

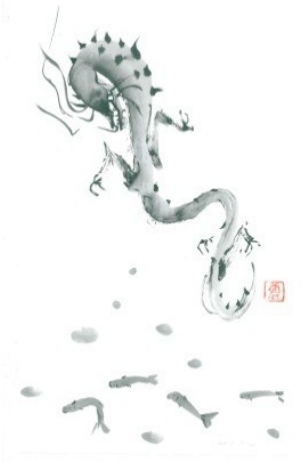

